\title{
Frequency of H.Pylori Infection With Correlation To Anthropometric Measures In Children Aged(2-12) years In Zagazig University Hospital
}

\author{
Usama Roshdy Elsafy ${ }^{1}$, Ahmed Mohammed Abdel Moniem ${ }^{1}$, Shimaa Muhammed \\ Muhammed Abdullah ${ }^{1}$ * \\ ${ }^{I}$ Pediatrics department,Faculty of Medicine, Zagazig University-Zagazig-Egypt
}

\section{*Corresponding author:}

\section{Shimaa Muhammed \\ Muhammed Abdullah \\ MBBCH- Faculty of Medicine - Zagazig University-Zagazig- \\ Egypt \\ Email:shymaashemais@gmail.c om}

$\begin{array}{ll}\text { Submit Date } & \text { 2019-07-09 } \\ \text { Revise Date } & 2019-08-20 \\ \text { Accept Date } & 2019-08-26\end{array}$

\begin{abstract}
Background: H. pylori infection is the most common microbial infection in the world. It has a long history of a relationship with individuals, so the accurate and early diagnosis of $\mathrm{H}$. pylori infection is a relevant problem. H. pylori stool antigen test is a reliable, very good, and reasonably priced screening test for $\mathrm{H}$. pylori infection, both before and after eradication that could identify foreign proteins (antigens) in stool samples that are related with H. pylori infection. Therefore, this test has been proposed for the diagnosis of infection. Objective: This study aimed to evaluate the frequency of $\mathrm{H}$. pylori infection and its correlation to anthropometric measures in children aged (2-12) years in pediatric outpatient clinic in Zagazig University Hospital. Methods: This cross sectional study comprised67 children their ages were from two to twelve years. H. pylori stool antigen test was done for all children recruited in this study, by a microplate-based ELISA assay. Results: Among studied group, a total of 36 children $(53.7 \%)$ had positive $\mathrm{H}$. pylori stool antigen test who suffered from gastro intestinal symptoms especially recurrent abdominal pain. There was no statistically significant difference between $\mathrm{H}$. pylori +ve $\& \mathrm{H}$. pylori -ve infected children as regarding all the anthropometric measures. $H$. pylori infection was correlated with abdominal distension. Conclusion: frequency of $\mathrm{H}$. pylori infection in children still high and a prevalent condition.We need further studies in this subject. H. pylori infection did not affect growth.
\end{abstract}

Keywords: H. pylori ; diagnosis; Growth.

\section{INTRODUCTION}

$\mathrm{T}$ he infection of Helicobacter pylori (H.pylori) in children is common throughout the world and more than fifty percent of the population around the world is infected. The prevalence shows a great variability among different countries [1].

The frequency of the infection varies among populations, extends from below $15 \%$ to more than $85 \%$ of the population [2].

The prevalence of the infection all over the schoolchildren in Egypt is $72.38 \%$ [3].

The infection of $\mathrm{H}$. pylori occurs early in children and persists forever $[4,5]$.

The infection of children with H. pylori leads to chronic gastritis, gastric ulcer, duodenal ulcer, gastric adenocarcinoma and gastric mucosa-associated lymphoid tissue (MALT) lymphoma [6].

Moreover, it causes extra gastro duodenal manifestations such as hematological, metabolic, cardiovascular, neurodegenerative and allergic disorders [7].

$\mathrm{H}$. pylori infection is related with iron deficiency anemia, although the degree of anaemia in the absence of peptic ulcer is usually modest $[8,9]$.

The diagnosis of $\mathrm{H}$. pylori infection can be by invasive methods like endoscopy of the upper gastrointestinal tract and tissue staining using gastric tissues gained by the endoscope. It may be diagnosed by noninvasive methods that include rapid urease test, culture for $\mathrm{H}$. pylori, urea breath 
test(UBT) and $\mathrm{H}$. pylori stool antigen test (HPSAT) [10].

Though the children acquire the infection during childhood, it is not obvious whether it affects the health of the children [4].

The infection of $\mathrm{H}$. pylori which gained in early childhood may have adverse impact on linear growth at school age later [11].

So, the available data regarding $\mathrm{H}$. pylori infection and its impact on growth in children remains controversial. Acute and chronic infections may impede linear growth by affecting the absorption of micronutrient, appetite, metabolism, and associated factors [12].

Although the growth of human is also influenced by factors such as diet, socioeconomic status, other infections, and genetics [13].

Hence, the estimation of the effect of the infection with $\mathrm{H}$. pylori on growth precisely is difficult owing to the number of potential confounders, many of which are insufficiently controlled in studies. There have been a lot of cross-sectional studies [14]. that point to either the presence of significant association between $\mathrm{H}$. pylori and decreased height, weight, or growth or not. These studies all are restricted by the inability to establish temporal precedence [15].

Fecal antigen testing stays a reliable, very good, and reasonably priced screening test for $\mathrm{H}$. pylori infection, both before and after eradication [16]. This laboratory test can identify foreign proteins (antigens) in stool samples that are related with $H$. pylori infection. Stool samples have high specificity and sensitivity, similar to the UBT, and they can likewise evaluate infection status after treatment. In any case, stool samples need patient compliance, are difficult to handle, and results are not promptly known [17].

Similarly, its sensitivity and specificity rely upon types of commercial test used, cut-off value, treatment status, and the interpretation of weakly positive results.

The European Society of Pediatric Gastroenterology and Nutrition (ESPGHAN) and The North American Society for Pediatric Gastroenterology and Nutrition
(NASPGHAN) guidelines show that approved Enzyme linked immunosorbent assay( ELISA) for H. pylori identification in stool can reliably decide whether $\mathrm{H}$. pylori has been eradicated in children [10].

The aim of this study was to evaluate the frequency of $\mathrm{H}$. pylori infection and its correlation to anthropometric measures in children.

\section{SUBJECTS AND METHODS}

Study Design and Population: This cross sectional study was conducted at the pediatric outpatient clinic in Zagazig University Hospital during the period from Mai 2018 to November2019. A total sample of 67 children with gastro intestinal tract (GIT) symptoms was included in the present study. After detailed history, clinical examination, investigations and examination of stool samples collected from all children .we divided these children according to the presence or absence of H.pylori in their stools into two main groups :H.pylori positive(+ve) $\&$ H.pylori negative(-ve) children.

Written informed consent was obtained from all participants ' parents and the study was approved by the research ethical committee of Faculty of Medicine, Zagazig University. The work has been carried out in accordance with the Code of Ethics of the World Medical Association (Declaration of Helsinki) for students involving humans .

\section{Subjects included in study:}

Children aged from two to twelve years and Children suffering from GIT symptoms (recurrent abdominal pain, nausea, vomiting, and no weight gain).

\section{Exclusion criteria:}

Children age below 2 years old and more than 12 years old, Children with recent history of taking anti $\mathrm{H}$. pylori treatment and Children suffering from recurrent abdominal pain due to appendicitis.

All children enrolled in this study were subjected to full medical history taking including family history, clinical examination including general examination including (pulse, temperature, blood pressure, respiratory rate), anthropometric measures including (weight, Length, Head circumference, Chest circumference, abdominal circumference, Mid-arm 
circumference, Upper segment).We used weight for age and length for age UK growth charts(218)years RCPCH (Royal college paediatrics and child health) in girls.

We used stature for age and weight for age percentiles in boys (2- 20) years developed by the national centre for health statistics in collaboration with the national centre for chronic disease prevention and health promotion. We also use WHO head circumference for age percentiles in boys and girls. We also use WHO arm circumference for age percentiles in boys and girls. We also use WHO chest circumference for age percentiles in boys and girls. We also use abdominal (waist) circumference for age percentiles Baby and kids size chart UK. We also use WHO upper segment for age percentiles in boys and girls. And complete clinical examination to detect any associated clinical signs.

The laboratory investigations which were done to all children were Complete blood count, C-reactive protein(CRP), liver function tests, Kidney function tests ,Stool analysis and $\mathrm{H}$. pylori antigen in stool.

\section{Laboratory Procedures:}

Complete blood counts were done by cell counter. The CRP was measured using CRP Quantikine ELISA kits (R\&D, Minneapolis, MN, USA) and H. Pylori antigen in stool was measured for all cases included in this study by a micro plate-based ELISA assay (Epitope Diagnostics, Inc. (EDI) Fecal Helicobacter pylori Antigen ELISA kit).

\section{3- Statistical analysis:}

Data were checked, entered and analyzed by using (SPSS version 22) (Statistical Package for the Social Sciences). Data were expressed as mean, standard deviation (SD) for quantitative variables, number and percentage for qualitative variables. Chi-squared test and student t test were used when appropriate $\mathrm{P}<0.05$ was considered statistically significant.

\section{RESULTS}

The present work was conducted on 67 children their ages were from two to twelve years of which 32 males and 35 females.
The prevalence of $\mathrm{H}$. pylori infection among the studied children who suffered from abdominal pain which is $(53.7 \%)$. Table (1)

There was a statistically significant difference $(\mathrm{p}=0.04)$ between $\mathrm{H}$. pylori +ve \&H. pylori ve infected children as regarding Family history with a higher percentage of +ve family history in $\mathrm{H}$. pylori -ve infected children (63.6\%).Also , There was no statistically significant difference between $\mathrm{H}$. pylori +ve $\&$ H. pylori - ve infected children as regarding age, sex, socio economic status. Table(2)

The percentages of distribution of different symptoms among the studied children suffering from abdominal pain and loss of appetite had the highest percentage $(100 \%)$ followed by those suffering from no increase of weight $(62.7 \%)$. Table (3)

There was a statistically significant difference $(\mathrm{p}=0.04)$ between $H$. pylori +ve $\&$ H. pylori -ve infected children as regarding Abdominal distension with a higher percentage in $\mathrm{H}$. pylori +ve infected children $(81.8 \%)$.

There was a statistically significant difference $(\mathrm{p}=0.016)$ between $\mathrm{H}$. pylori +ve $\&$ H. pylori -ve infected children as regarding diarrhea with a higher percentage of diarrhea in H. pylori -ve infected children (88.9\%).

There was no statistically significant difference between $\mathrm{H}$. pylori +ve \&H. pylori -ve infected children as regarding Abdominal pain, Vomiting, Fever, No increase of weight, Loss of weight and decrease appetite. Table (4)

There was no statistically significant difference between $\mathrm{H}$. pylori +ve \&H. pylori - ve infected children as regarding all the anthropometric measures. Table (5)

There was no statistically significant difference between $\mathrm{H}$. pylori +ve \&H. pylori -ve infected children as regarding laboratory investigations (Red blood cells(RBCS), White blood cells(WBCS), Hemoglobin(HB), Platelets(PLT). Table (6)

The percentages of distribution of stool examination among the studied children suffering from Entamoeba Histolytica cyst alone had the highest percentage $(70,1 \%)$ followed by those suffering from Entamoeba Histolytica \& giardia cysts (23.9\%)and normal (6\%).(table7) 
Table (1): H. pylori antigen in stool .

\begin{tabular}{|l|l|l|}
\hline H. pylori & No & $\%$ \\
\hline -ve & 31 & 46.3 \\
\hline$+\mathrm{ve}$ & 36 & 53.7 \\
\hline
\end{tabular}

Table (2) : Relationship between H. pylori infection and demographic data of the studied children.

\begin{tabular}{|c|c|c|c|c|c|c|}
\hline \multirow[t]{3}{*}{ Variables } & \multicolumn{4}{|c|}{ H. pylori } & \multirow[t]{3}{*}{$\mathrm{X}^{2}$} & \multirow[t]{3}{*}{$\mathbf{P}$} \\
\hline & \multicolumn{2}{|c|}{-ve } & \multicolumn{2}{|c|}{ +ve } & & \\
\hline & No & $\%$ & No & $\%$ & & \\
\hline \multicolumn{7}{|l|}{ Age (years) } \\
\hline$<8$ & 21 & 51.2 & 20 & 48.8 & \multirow[t]{2}{*}{1.04} & \multirow[t]{2}{*}{$0.3 \mathrm{NS}$} \\
\hline 8 & 10 & 38.5 & 16 & 61.5 & & \\
\hline \multicolumn{7}{|l|}{ sex } \\
\hline Male & 12 & 37.5 & 20 & 62.5 & \multirow[t]{2}{*}{1.89} & \multirow[t]{2}{*}{$0.16 \mathrm{NS}$} \\
\hline Female & 19 & 54.3 & 16 & 45.7 & & \\
\hline \multicolumn{7}{|l|}{ Family history } \\
\hline$-\mathrm{ve}$ & 17 & 37.8 & 28 & 62.2 & \multirow[t]{2}{*}{39.97} & \multirow[t]{2}{*}{$0.04 *$} \\
\hline$+\mathrm{ve}$ & 14 & 63.6 & 8 & 36.4 & & \\
\hline \multicolumn{7}{|c|}{ Socioeconomic status } \\
\hline Low & 9 & 47.4 & 10 & 52.6 & \multirow[t]{2}{*}{0.01} & \multirow[t]{2}{*}{$0.09 \mathrm{NS}$} \\
\hline Moderate & 22 & 45.8 & 26 & 54.2 & & \\
\hline
\end{tabular}

Table (3): History and clinical presentations of the studied children.

\begin{tabular}{|l|l|l|}
\hline Variables & No & $\%$ \\
\hline Clinical data: & & \\
\hline Abdominal pain & 67 & 100.0 \\
\hline Decrease appetite & 67 & 100.0 \\
\hline No increase of weight & 42 & 62.7 \\
\hline Loss of weight & 25 & 37.3 \\
\hline Vomiting & 18 & 26.9 \\
\hline Abdominal distention & 11 & 16.4 \\
\hline Diarrhea & 9 & 13.4 \\
\hline Fever & 0 & 0.0 \\
\hline
\end{tabular}


Table (4): Relationship between $H$. pylori infection and clinical symptoms of the studied children .

\begin{tabular}{|c|c|c|c|c|c|c|c|}
\hline & \multicolumn{4}{|c|}{ H. pylori } & \multirow[t]{3}{*}{$\mathbf{X}^{2}$} & \multirow[t]{3}{*}{$\mathbf{P}$} & \multirow{3}{*}{$\begin{array}{l}\text { OR } \\
(95 \% \mathrm{CI})\end{array}$} \\
\hline & \multicolumn{2}{|c|}{-ve } & \multicolumn{2}{|c|}{ +ve } & & & \\
\hline & No & $\%$ & No & $\%$ & & & \\
\hline \multicolumn{8}{|l|}{ Abdominal pain } \\
\hline Yes & 31 & 46.3 & 36 & 53.7 & 0.0 & $1.0 \mathrm{NS}$ & \\
\hline \multicolumn{8}{|l|}{ Abdominal distension } \\
\hline No & 29 & 51.8 & 27 & 48.2 & \multirow[t]{2}{*}{4.18} & \multirow[t]{2}{*}{$0.04 *$} & \multirow[t]{2}{*}{4.83} \\
\hline Yes & 2 & 18.2 & 9 & 81.8 & & & \\
\hline \multicolumn{8}{|l|}{ Vomiting } \\
\hline No & 24 & 49.0 & 25 & 51.0 & \multirow[t]{2}{*}{0.54} & \multirow[t]{2}{*}{$0.46 \mathrm{NS}$} & \multirow{2}{*}{$\begin{array}{l}1.5 \\
(0.44-5.3)\end{array}$} \\
\hline Yes & 7 & 38.9 & 11 & 61.1 & & & \\
\hline \multicolumn{8}{|l|}{ Diarrhea } \\
\hline No & 23 & 39.7 & 23 & 60.3 & \multirow[t]{2}{*}{5.75} & \multirow[t]{2}{*}{$0.016^{*}$} & \\
\hline Yes & 8 & 88.9 & 1 & 11.1 & & & \\
\hline \multicolumn{8}{|l|}{ Fever } \\
\hline No & 31 & 46.3 & 36 & 53.7 & \multirow[t]{2}{*}{0.0} & \multirow[t]{2}{*}{$1.0 \mathrm{NS}$} & \\
\hline Yes & 0 & & & & & & \\
\hline \multicolumn{8}{|l|}{ Weight } \\
\hline No increase & 20 & 47.6 & 22 & 52.4 & \multirow[t]{2}{*}{0.08} & \multirow[t]{2}{*}{$0.77 \mathrm{NS}$} & \multirow{3}{*}{$\begin{array}{l}1.16 \\
(0.38-3.56)\end{array}$} \\
\hline Loss of weight & 11 & 44 & 14 & 56 & & & \\
\hline Loss of appetite & 31 & 46.3 & 36 & 53.7 & 0.0 & $1.0 \mathrm{NS}$ & \\
\hline
\end{tabular}

*p value $<0.05$ means statistical significant difference.
(*) means significant as $\mathrm{p}$ value $<0.05$
$\mathbf{X}^{2}$ : Chi-square test.

NS :means non -significant as $p$ value $>0.05$

Table (5 ): Relationship between H.pylori infection and anthropometric measures among the studied children.

\begin{tabular}{|c|c|c|c|c|}
\hline \multirow[t]{2}{*}{ Variables } & \multicolumn{2}{|l|}{ H. pylori } & \multirow[t]{2}{*}{$t$} & \multirow[t]{2}{*}{$\mathbf{P}$} \\
\hline & -ve & +ve & & \\
\hline \multicolumn{5}{|l|}{ Weight,Kg } \\
\hline XSD & 25.28 .8 & 24.910 .7 & \multirow[t]{2}{*}{0.12} & \multirow[t]{2}{*}{$0.89 \mathrm{NS}$} \\
\hline Range & $14-45$ & $10-50$ & & \\
\hline \multicolumn{5}{|l|}{ Length,Cm } \\
\hline XSD & 120.712 .7 & 118.318 .8 & \multirow[t]{2}{*}{0.6} & \multirow[t]{2}{*}{$0.54 \mathrm{NS}$} \\
\hline Range & $94-141$ & $83-156$ & & \\
\hline \multicolumn{5}{|c|}{$\begin{array}{l}\text { Head } \\
\text { circumference, Cm }\end{array}$} \\
\hline XSD & 511.5 & 51.13 & \multirow[t]{2}{*}{0.09} & \multirow[t]{2}{*}{$0.92 \mathrm{NS}$} \\
\hline Range & $48-53$ & $45-55$ & & \\
\hline \multicolumn{5}{|c|}{$\begin{array}{l}\text { Chest } \\
\text { circumference, } \mathrm{Cm}\end{array}$} \\
\hline XSD & 62.38 .9 & 628.5 & \multirow[t]{2}{*}{0.12} & \multirow[t]{2}{*}{$0.9 \mathrm{NS}$} \\
\hline Range & $52-82$ & $49-82$ & & \\
\hline \multicolumn{5}{|c|}{$\begin{array}{l}\text { Abdominal } \\
\text { circumference, Cm }\end{array}$} \\
\hline XSD & 60.36 .8 & 60.78 .1 & 0.22 & $0.82 \mathrm{NS}$ \\
\hline
\end{tabular}




\begin{tabular}{|c|c|c|c|c|}
\hline Range & $53-75$ & $48-77$ & & \\
\hline \multicolumn{5}{|c|}{$\begin{array}{l}\text { Mid-arm } \\
\text { circumference, } \mathrm{Cm}\end{array}$} \\
\hline XSD & 19.22 .5 & 19.46 .2 & \multirow[t]{2}{*}{0.18} & \multirow[t]{2}{*}{$0.85 \mathrm{NS}$} \\
\hline Range & $15-24$ & $13-52$ & & \\
\hline \multicolumn{5}{|c|}{ Upper segment,Cm } \\
\hline XSD & 55.16 .4 & 5.36 .4 & \multirow[t]{2}{*}{1.3} & \multirow{2}{*}{$0.18 \mathrm{NS}$} \\
\hline Range & $41-64$ & $42-63$ & & \\
\hline
\end{tabular}

Table (6): Relationship between H.pylori infection and laboratory investigations among the studied children:

\begin{tabular}{|l|l|l|l|l|}
\hline Variables & -ve & +ve & t & P \\
\hline WBCs & 7.62 .4 & 8.02 .7 & 0.6 & $0.5 \mathrm{NS}$ \\
\hline RBCs & 4.70 .3 & 4.6 .3 & 0.4 & $0.68 \mathrm{NS}$ \\
\hline $\mathrm{Hb}$ & 12.50 .7 & 12.40 .7 & 0.34 & $0.72 \mathrm{NS}$ \\
\hline PLT & 325.249 .6 & 313.966 .8 & 0.7 & $0.4 \mathrm{NS}$ \\
\hline
\end{tabular}

NS: means non -significant as $\mathrm{p}$ value $>0.05$.

$\mathbf{t}$ : student $\mathrm{t}$ test .

$*$ p value $<0.05$ means statistical significant difference.

Table (7): Stool examination of the studied children.

\begin{tabular}{|l|l|l|}
\hline Variables & No & $\%$ \\
\hline Normal & 4 & 6.0 \\
\hline Entamoeba Histolytica cyst & 47 & 70.1 \\
\hline Entamoeba Histolytica \& giardia cysts & 16 & 23.9 \\
\hline
\end{tabular}

\section{DISCUSSION}

H.pylori is a common microbial infection and infects approximately half of the total population all over the world. The frequency of infection with $\mathrm{H}$. pylori in the world is variable and relies upon various factors for example, age, ethnicity, geographical and socioeconomic status [18].

It influences about $20 \%$ of the population in developed countries and over $90 \%$ in the developing world [19].

Testing H.pylori antigen in stool stays a reliable, screening test for $\mathrm{H}$. pylori infection, both pre and post eradication [16].

This laboratory test can identify foreign proteins in fecal samples that are correlated with $\mathrm{H}$. pylori infection. Fecal samples have high specificity and sensitivity, as the UBT, and they can also evaluate infection state post treatment. In any case, Fecal samples need patient compliance, are not easy to handle, and results are not promptly identified [17].

Fecal identification of $\mathrm{H}$. pylori by approved ELISA can reliably detect whether H. pylori has been eradicated in children [10].

Our study aimed to evaluate the frequency of $\mathrm{H}$. pylori infection and its correlation to anthropometric measures in children aged (2-12) years in pediatric outpatient clinic in Zagazig University Hospital.

The data obtained show that the prevalence of $\mathrm{H}$. pylori infection among the studied children who suffered from abdominal pain is $(53.7 \%)$ (36 children from 67 children) which is lower than results detected by AbuZekry et al. [20]. who studied the frequency of helicobacter pylori infection among Egyptian children presenting with gastrointestinal manifestations and revealed that it was $70 \%$.. Simultaneously, our data is much higher than data published by Awuku et 
al. [21]. who studied the Prevalence of helicobacter pylori infection in children between the ages of 5-16 years living in two rural communities in the Upper West region of Ghana and revealed that it was $14.2 \%$. but this finding is nearer to the data published by Yousab Feiby et al. [22]. who studied the prevalence of $\mathrm{H}$. pylori infection among Egyptian children and it was 58,3\%.

There was a statistically significant difference $(\mathrm{p}=0.04)$ between $\mathrm{H}$. pylori +ve $\&$ H. pylori -ve infected children as regarding family history with a higher percentage of +ve family history in $\mathrm{H}$. pylori -ve infected children $(63.6 \%)$. In our study, 14 children $(63.6 \%)$ who were H.pylori stool antigen test(HPSAT) negative, had a positive family history of the same gastrointestinal symptoms, So there was no a significant association between the $\mathrm{H}$. Pylori infections and the positive family history of the same gastrointestinal symptoms. this data is not concomitant with that published by Mahmud et al. [23]. who found that there was a significant association between the $\mathrm{H}$. Pylori infections and the positive family history of gastrointestinal symptoms.

There was no a significant difference between $\mathrm{H}$. pylori +ve and H. pylori -ve groups regarding the sex as we had 20male $(62.5 \%)$ and 16 female $(45.7 \%)$ H. pylori +ve children simultaneously we had 12 male $(37.5 \%)$ and19 female $(54.3 \%)$ H. pylori -ve children. In our study, males were more likely to have $\mathrm{H}$. pylori infection $(62.5 \%)$ in comparison to the females $(45.7 \%)$. This finding is in consistent with a study carried out in East of Sudan by Abbas et al. [24]. In contrary to these findings, Bin Mohanna et al. [25]. found that girls in Yemen were more affected than boys. However, Biernat et al. [26]. showed that no differences in the prevalence of infection between boys and girls.

There is no significant difference between $\mathrm{H}$. pylori +ve and $\mathrm{H}$. pylori -ve children regarding the age as the $\mathrm{p}$ value was 0.3. In our study, the incidence of $\mathrm{H}$. pylori infection was common among the two age groups of studied children although $\mathrm{H}$. pylori infection was more in children above 8 years $(61.5 \%)$. In East of Sudan, Abbas et al. [24]. showed the prevalence of infection was higher in the age group more than 15 years $(23.1 \%)$.this shows that the prevalence of $h$. pylori infection increases with age.

Also there was no significant difference regarding the socioeconomic status between $H$. pylori +ve \& $H$. pylori - ve infected children as $(\mathrm{P}=0.09)$. In our study, the incidence of $\mathrm{H}$. pylori infection was common among all studied children. Although $54.2 \%$ of the children with HPSAT positivity belonged to moderate socioeconomic status this data is not concomitant with that published by Mahmud et al. [23]. who found that $78.9 \%$ of the children with HPSAT positivity belonged to low socioeconomic class. This may be explained by there may be other risk factors leading to acquisition of infection which may be sanitary conditions, level of educational background.

The infection of $\mathrm{H}$. pylori in children may be either clinically silent or associated with nonspecific sign or symptoms, which are seen in various childhood complaints [27].

Regarding the clinical point of view, the studied children were suffering from abdominal pain, loss of appetite $(100 \%)$ no increase of weight $(62.7 \%)$, loss of weight (37.3\%), vomiting (26.9\%), abdominal distention (16.45\%) and diarrhea $(13.4 \%)$.although the majority of $h$. pylori infection was associated with Abdominal distension $(81.8 \%)$. the prevalence of $h$. pylori infection among the children suffering from abdominal pain or loss of appetite was $(53.7 \%)$.

In contrary to these findings, a study carried out in East of Sudan by Abbas et al[24].who found that the most frequent symptoms associated with $\mathrm{H}$. pylori infections were nausea $(25.5 \%)$, followed by gastric pain $(24.5 \%)$ and heart pain $(20.2 \%)$.

There was a statistically significant difference $(\mathrm{p}=0.04)$ between $\mathrm{H}$. pylori +ve \& H. pylori -ve infected children as regarding Abdominal distension with a higher percentage in $\mathrm{H}$. pylori +ve infected children $(81.8 \%)$.This is consistent with CastilloMontoya et al. [28]. who found that a significant positive association between $\mathrm{H}$. pylori and bloating $(\mathrm{p}=0.016)$. 
There was a statistically significant difference $(\mathrm{p}=0.016)$ between $\mathrm{H}$. pylori +ve $\&$ H. pylori -ve infected children as regarding diarrhea with a higher percentage of diarrhea in H. pylori -ve infected children (88.9\%).our study found that $\mathrm{H}$. pylori infection was not associated with diarrhea in contrary to Castillo-Montoya et al. [28]. who found that a significant positive association between $\mathrm{H}$. pylori and diarrhea $(\mathrm{p}=0.0389)$.

There was no statistically significant difference between $\mathrm{H}$. pylori +ve \&H. pylori -ve infected children as regarding Abdominal pain, Vomiting, Fever, No increase of weight, Loss of weight and decrease appetite. This is in concomitant with Abu-Zekry et al. [20]. who found no statistically significant differences were found between the 13C-UBT result among patients with vomiting $(\mathrm{P}=1.00)$. Similarly, Castillo-Montoya et al. [28]. who found that no significant association between H. pylori infection and weight loss .In our study there was no significant association between h. pylori infection and abdominal pain this is in concomitant with Badr et al. [29]. who found that there was no a direct role for $\mathrm{H}$. pylori infection as a causative agent for Recurrent Abdominal Pain (RAP) in children .also Mansour et al. [30]. who found that there was no association between RAP and $\mathrm{H}$. pylori infection .In contrary to CastilloMontoya et al. [28]. who found a significant positive association between $\mathrm{H}$. pylori and epigastric pain $(\mathrm{p}<0.001)$, recurrent periumbilical pain $(\mathrm{p}<0.001)$.

In our study, there was no statistically significant difference between $\mathrm{H}$. pylori +ve $\&$ H. pylori -ve infected children as regarding all the anthropometric measures i.e. H. pylori infection does not affect growth. Similarly $\mathrm{Xu}$ et al. [31]. found that $H$. pylori infection was not associated with overweight/obesity observed from the retrospective study in this Chinese population. In contrary to Abbas et al. [24]. who found that most of the positive cases were underweight. According to Kopacova et al. [32]., the chronic infection of H. pylori appeared to be associated with short stature in children. H. pylori infection did not influence body weight and body mass index either in adults or children and adolescents. Many factors can affect the growth in children and stature, such as nutrition, chronic inflammation, and gastrointestinal disease.

There was also no statistically significant difference between $\mathrm{H}$. pylori $+\mathrm{ve} \& \mathrm{H}$. pylori -ve infected children as regarding laboratory investigations (RBCS, WBCS, Hb, PLT).In contrary to $\mathrm{Yu}$ et al. [33]. who found that a significant difference was found between various $\mathrm{WBC}$ quartiles for $\mathrm{H}$ pylori infection $(P=0.001)$.This may be explained by our study was cross sectional study in contrary to their cohort study which enabled them to follow the children properly. Also Baxendell et al. [34]. found that $H$. pylori-infected children had lower red blood cell counts $(p=0.005)$ compared with non-infected .also found that an association between $\mathrm{H}$. pylori infections and reduced platelet indices in young Ethiopian school children.

In our study, we examined stool samples of all studied children and showed that 4 children $(6 \%)$ revealed normal stool examination, 47 children $(70.1 \%)$ revealed Entamoeba histolytica cyst, 16 children (23.9\%) revealed Entamoeba Histolytica \& giardia cysts. Entamaeba histolytica, Giardia lamblia and H. pylori are considered the most common infectious agents affecting human beings in developing countries [35]. In our study, intestinal parasites were detected in $94 \%$ of upper gastrointestinal symptomatic patients with Entamoeba histolytica cyst $(70.1 \%)$ being the most prevalent. This is consistent with results of other studies established in Egypt revealing that Entamoeba histolytica was the most prevalent protozoan infection followed by Giardia lamblia infection [36,37]. In contrary to Kazemian et al [38]. who found that among 37 children with H. pylori infection in Iran, they reported Giardia lamblia and Entamoeba. histolyticain $29.7 \%$, \&10.8\% respectively. This study showed that Giardia lamblia was the most prevalent parasite associated with $\mathrm{H}$. pylori infection.

\section{CONCLUSION}

The frequency of $\mathrm{H}$. pylori infection in children still high and a prevalent problem .We need more further studies in this subject to know all predisposing factors of $\mathrm{H}$. pylori infection. H. pylori infection did not affect growth of children. 
Conflict of Interest: Non declared.

Funding: No funding sources.

\section{REFERENCES}

1-Hooi JKY, Lai WY, Ng WK, Suen MMY, Underwood FE, Tanyingoh D, et al. Global prevalence of Helicobacter Pylori infection: systemic review and Meta-analysis. Gastroenterology. 2017;153(2): 420-429. doi : 10.1053/j.gastro.2017.04.022. Epub 2017 Apr 27.

2-Bruce MG, Maaroos HI. Epidemiology of Helicobacter pylori infection. Helicobacter.2008;13:1-6.doi: 10.1111/j.15235378.2008.00631.x.

3-Mohammad MA, Hussein L, Coward A, Jackson SJ. Prevalence of Helicobacter pylori infection among Egyptian children: impact of social background and effect on growth. Public Health Nutr. 2007; 11(3): 230-236. doi: $10.1017 / \mathrm{S} 1368980007000481$.

4-Torres J, Perez-Perez G, Goodman KJ, Atherton JC, Gold BD, Harris PR, et al. A comprehensive review of the natural history of Helicobacter pylori infection in children. Arch Med Res. 2000;31(5):431-469. doi: .-()10.1016/S0188-4409(00)00099-0.

5-Muhsen K, Jurban M, Goren S , Cohen D. Incidence, age of acquisition and risk factors of Helicobacter pylori infection among Israeli Arab infants. J Trop Pediatr . 2012;58(3): 208213. doi: $10.1093 /$ tropej/fmr068 .

6-Graham DY. Helicobacter pylori update: gastric cancer, reliable therapy, and possiblebenefits.Gastroenterol.2015;148(4):71 9-731. doi:10.1053/j.gastro.2015.01.040.Epub 2015 Feb 2.

7-Chmiela M, Gajewski A, Rudnicka K. Helicobacter pylori vs coronary heart disease searching for connections World $\mathbf{J}$ Cardiol.2015, 7(4): 187-203. doi: 10.4330/wjc.v7.i4.187.

8-Parkinson AJ, Gold BD, Bulkow L, Wainwright RB, Swaminathan Bm, Khanna B, et al. High Prevalence of Helicobacter pylori in the Alaska native population and association with low serum ferritin levels in young adults. Clin Diagn Lab Immunol. 2000;7(6): 885-888. doi: 10.1128/cdli.7.6.885888.2000 .

9-DiGirolamo AM, Perry GS, Gold BM, Parkinson A, Provost EM , Parvanta I, et al. Helicobacter pylori, anemia, and iron deficiency: relation- ships explored among Alaska native children. Pediatr Infect Dis J. 2007; 26(10): 927-934.
10-Koletzko S, Jones NL, Goodman KJ, Gold B, Rowland M, Cadranel S, et al. H. pylori Working Groups of ESPGHAN and NASPGHAN. Evidence-based guidelines from ESPGHAN and NASPGHAN for Helicobacter pylori infection in children. $\mathrm{J}$ Pediatr Gastroenterol Nutr. 2011; 53(2): 230-243.

11-Muhsen K, Goren S , Cohen D . Helicobacter pylori infection in early childhood and growth at school age. Helicobacter. 2015;20(6): 410417. doi: 10.1111/hel.12227. Epub 2015 Apr 13.

12-Pacifico L, Osborn JF, Tromba V, Romaggioli S, Bascetta S,Chiesa C. Helicobacter pylori infection and extragastric disorders in children: A critical update. World J Gastroenterol. 2014;20(6): 1379-1401.doi: 10.3748/wjg.v20.i6.1379.

13-Goodman KJ, Joyce SL , Ismond KP. Extragastric diseases associated with Helicobacter pylori infection.Curr Gastroenterol Rep.2006;8(6):458-464 doi.org/10.1007/s11894-006-0035-3.

14-Gulcan M, Ozen A, Karatepe HO, Gulcu D , Vitrinel A . Impact of H. pylori on growth: is the infection or mucosal disease related to growth impairment? Dig Dis Sci. 2010;55(10): 2878-2886. doi: 10.1007/s10620-009-1091-y. Epub 2010 Jan 29.

15-Goodman KJ, Correa P, Mera R, Yepez MC, Cerón C,Campo C, et al. Effect of Helicobacter pylori infection on growth velocity of school-age Andean children. Epidemiology. $\quad 2011 ; 22(1)$ : 118-126. doi: 10.1097/EDE.0b013e3181fe7e31.

16-Leal YA, Cedillo-Rivera R, Simon JA, Velzquez JR, Flores LL, Torres J. Utility of stool sample-based tests for the diagnosis of Helicobacter pylori infection in children. $\mathbf{J}$ Pediatr Gastroenterol Nutr. 2011;52(6): 718728. doi: 10.1097/MPG.0b013e3182077d33.

17-Mafertheine P, Megraud F, O'Morain C, Hungin AP , Hungin AP,Axon A, et al . Current concepts in the management of Helicobacter pylori infection-The Maastricht 2-2000 Consensus Report. Aliment Pharmacol Ther.2002;16(2): 167-180. doi/full/10.1046/j.1365-2036.2002.01169.x

18-Calvet X, Ramırez Lazaro MJ, Lehours P , Megraud F . Diagnosis and epidemiology of Helicobacter pylori infection. Helicobacter. 2013;18(1): 5-11. doi: 10.1111/hel.12071.

19-Rhee KH, Park JS , Cho MJ. Helicobacter pylori: bacterial strategy for incipient stage and persistent colonization in human gastric niches. Yonsei Med J. 2014;55(6): 1453-1466. doi: 10.3349/ymj.2014.55.6.1453. 
20-Abu-Zekry MA, Hashem M, Ali AA, Mohamed IS. Frequency of Helicobacter pylori infection among Egyptian children presenting with gastrointestinal manifestations. J Egypt Public Health Assoc. 2013;88(2): 7478.

doi:

10.1097/01.EPX.0000430958.09388.0e.

21-Awuku YA, Simpong DL, Alhassan IK, Tuoyire DA, Afaa T, Adu P. Prevalence of helicobacter pylori infection among children living in a rural setting in Sub-Saharan Africa. BMC Public Health. 2017; 17: 360. doi: 10.1186/s12889-017-4274-z.

22-Yousab Feiby GK, Nesrin MH, Mesbah Badr AM . Prevalence of Helicobacter pylori infection among $\beta$-thalassemia major children with recurrent abdominal pain at Suez Canal University Hospital. Egypt J Haematol.2015;40(2): 74-49. doi: 10.4103/1110-1067.161292.

23-Mahmud S, Shah, SAH, Ali S. Frequency of Helicobacter Pylori Infection in Children with recurrent abdominal pain. Pak Armed Forces Med J. 2015; 65(2): 358-362. https://www.pafmj.org/index.php/PAFMJ/artic le/view/904.

24-Abbas M, Sharif FA, Osman SM, Osman AM, El Sanousi SM, Magzoub M, et al. Prevalence and Associated Symptoms of Helicobacter pylori Infection among Schoolchildren in Kassala State, East of Sudan. Interdiscip Perspect Infect Dis.2018;2018: 5.doi.org/10.1155/2018/4325752.

25-Bin Mohanna MA, Al-Zubairi LM , Sallam AK. Prevalence of helicobacter pylori and parasites in symptomatic children examined for helicobacter pylori antibodies, antigens, and parasites in Yemen. Saudi Med J. 2014; 35(11): 1408-1411. PMCID: PMC4362138 PMID:25399223.

26-Biernat MM, Iwańczak B, Bińkowska A, Grabińska J , Gościniak G. The prevalence of helicobacter pylori infection in symptomatic children: A 13-year observational study in the lower silesian region. Adv Clin Exp Med. 2016;25(2): 303-308. doi: 10.17219/acem/44372.

27-Ceylan A, Kırımi E, Tuncer O, Türkdogan $\mathrm{K}$, Ariyuca S, Ceylan1 N . Prevalence of helicobacter pylori in children and their family members in district in Turkey. J Health Popul Nutr. 2007;25(4): 422-427. PMCID: PMC2754017 PMID: 18402185.

28-Castillo-Montoya V, Ruiz-Bustos E, Valencia-Juillerat ME, Álvarez-Hernández G, Sotelo-Cruz N. Detection of Helicobacter pylori in children and adolescents using the monoclonal copro antigen immunoassay and its association with gastrointestinal diseases. Cir Cir. 2017;85(6): 27-33. doi: 10.1016/j.circen.2016.05.003.

29-Badr MA, El-Saadany HF, Ali AS , Abdelrahman D. Study of H. pylori infection in children with recurrent abdominal pain attending the pediatrics outpatient clinic of Zagazig University Hospitals.J Egypt Soci Parasitol 2012;42(3): 735-740. doi: 25.10.12816/0006357.

30-Mansour MMHK, Al Hadidi KhM , Omar MA - Helicobacter pylori and recurrent abdominal pain in children: Is there any relation? Trop Gastroenterol.2012;33(1):55-61. doi: http://dx.doi.org/10.7869/tg.2012.9.

31-Xu MY, Liu L, Yuan BS, Yin J, Lu QB. Association of obesity with Helicobacter pylori infection: A retrospective study. World $\mathrm{J}$ Gastroenterol. 2017;23(15):2750-2756. doi: 10.3748/wjg.v23.i15.2750.

32-Kopacova M, Koupil I, Seifert B, Fendrichova M S, Spirkova J, Vorisek V, et al. Blood pressure and stature in Helicobacter pylori positive and negative persons. World $\mathbf{J}$ Gastroenterol. 2014;20(19): 5625-5631. doi: 10.3748/wjg.v20.i19.5625.

33-Yu YY, Cai JT, Song ZY, Tong YL, Wang J H. The associations among Helicobacter pylori infection, white blood cell count and non-alcoholic fatty liver disease in a large Chinese population. Medicine. 2018;97(46):e13271.doi: 10.1097/MD.0000000000013271.

34-Baxendell $K$, Walelign $S$, Tesfaye $M$, Wordofa M, Abera D, Mesfin A,et al. Association between infection with Helicobacter pylori and platelet indices among school-aged children in central Ethiopia: a cross-sectional study BMJ Open. 2019;9(4):e027748.

http://dx.doi.org/10.1136/bmjopen-2018027748.

35-Sabet EA, El-hadi HA, Mohamed DS, Sheneef A, Fattouh $M$,Mamdouh M.Gastritis; Helicobacter pylori or Giardia lamblia infection or both. Egyptian $\mathrm{J}$ Med Microbiol.(2009); 18(4):165178.https://www.semanticscolar.org.

36- Bakr IM, Arafa NA, Ahmed MA, Mostafa MH, Mohamed MK. Prevalence of intestinal parasitosis in a rural population in Egypt, and its relation to socio-demographic characteristics. J Egypt Soc Parasitol.(2009); 39(1): 371-381.https://www.ncbi.nlm.nih.gov.

37- Zaytoun SSH, Abd Ella OH, Ghweil AAR, Hussien SM Ayoub HA. Prevalence of 
intestinal parasitosis among male youth in Qena Governorate (Upper Egypt), and its relation to socio-demographic characteristics and some morbidities. Life Sci J.(2013); 10(3): 658-663.https://www.researchgate.net.

38-Kazemian H, Shavalipour A, Mohebi R, Ghafurian S, Aslani S,Makeki A, et al. Estimation of the parasitic infection prevalence in children with Helicobacter pylori infection in Ilam City(2012-2013). Arch of Pediatr Infec Dis (2014); 2:.doi:10.5812/pedinfect.15294.

To Cite This Article: Elsafy UR, Abdel Moniem AM, Abdullah SM. Frequency of H.Pylori Infection With Correlation To Anthropometric Measures In Children Aged (2-12) years In Zagazig University Hospital. Zumj 2020; 26(5): doi: 10.21608/zumj.2019.14292.1303

abdullah, S., Elsafy, U., Abdel Moniem, A. Frequency of H.Pylori Infection With How to cite Correlation To Anthropometric Measures In Children Aged (2-12) years In Zagazig University Hospital. Zagazig University Medical Journal, 2020; (735-745): -. doi: 10.21608/zumj.2019.14292.1303 